\title{
Derecho humano a la paz
}

\section{RESUMEN}

El derecho humano a la paz viene siendo una propuesta fundamental desde numerosos sectores de la sociedad civil, juristas, académicos y activistas por la paz y los derechos humanos desde hace varias décadas. Pese a que el derecho a vivir en paz es una idea consustancial al género humano, la pretensión de normativizarlo y que quede plasmado como un derecho humano reconocido por las Naciones Unidas y estados miembro es relativamente reciente y está viviendo en los últimos años una etapa clave.

En este artículo se pretende definir el concepto y exponer algunas de sus características, presentar el estado de la cuestión y el proceso de codificación en las Naciones Unidas, y por último desentrañar algunos de los obstáculos a los que se enfrenta. La intención es por encima de todo defender y justificar la conveniencia y necesidad del derecho humano a la paz.

Palabras clave: Derecho humano, paz, observatorio.

\section{ABSTRACT}

The human right to peace is a fundamental proposal from many sectors of civil society, lawyers, academics and peace and human rights activists for several decades. Although the right to live in peace is an idea inherent to the human race, the aim of taking it as a norm and translate as a human right recognized by the United Nations and Member States is relatively recent and is living in recent years a key stage.

This article is intended to define the concept and expose some of its characteristics, present status of the issue and the codification process at the United Nations, and finally unravel some of the obstacles that it faces. The intention is above all to defend and justify the convenience and necessity of the human right to peace.

Key words: human rights, peace, observatory.

\section{El derecho a la paz}

Para entender lo que es el derecho a la paz nos puede valer una primera definición de Diego Uribe Vargas:

(el derecho a la paz es) el derecho de todo individuo a contribuir a los esfuerzos de paz, comprendiendo el rechazo a participar en preparativos militares, y el derecho colectivo de todo Estado a beneficiarse del pleno respeto por parte de los otros Estados, de los principios de no utilización de la fuerza, de no agresión, de solución pacífica de diferendos, de las convenciones de Ginebra y de los protocolos adicionales y de norma similares, así como la puesta en práctica de una política a favor del desarme general y completo bajo control internacional. (en revista Cultura de Paz 2011:23).

Esta idea del derecho a la paz parte quizás en lo explícito de una paz negativa, centrada en la erradicación de la guerra, pero el derecho a la paz va más allá de eso cuando toma en consideración los conceptos de paz positiva y de cultura de paz, con una pretensión más ambiciosa y holística sobre las relaciones humanas en general y sobre los derechos humanos en particular. El derecho a la paz pretende no sólo establecer bases para la transformación de conflictos y el desarme (en línea con el pacifismo tradicional) sino también, vincularse con el desarrollo socioeconómico y las situaciones de violencia estructural y con el pleno ejercicio y respeto a todos los derechos humanos, que también afectan con contundencia sobre nuestras posibilidades de vivir en paz.

Otro autor de referencia en el derecho a la paz, Héctor Gros Espiell, entiende que existe una "conciencia viva y creciente en la opinión pública mundial" del pacifismo y la cultura de paz, y que por lo tanto, esto debería verse proyectado en el derecho, "un derecho que no puede y no debe permanecer ajeno a la realidad $\mathrm{y}$ a las necesidades individuales y colectivas que tiene la humanidad" (1986: 523). Es decir, el derecho a la paz viene a dar respuesta a las múltiples emergencias

1 Licenciado en Ciencias Políticas, especialista en Estudios Internacionales de Paz, Conflictos y Desarrollo de la Universidad Jaume I, España. 
globales, teniendo en cuenta los déficits en la aplicación de los derechos humanos y la persistencia de violencias en todos los niveles.

Gros Espiell defiende que la paz es un valor de la civilización y la cultura humana y que por lo tanto no solo debemos defenderla y promoverla como un principio ético, sino también tratar de darle forma jurídica. Es decir, del mismo modo en que se han considerado ciertos valores y principios como universales al género humano, debe ser considerada la paz.

\section{¿Por qué un Derecho Humano a la} Paz?

El derecho humano a la paz, aún no codificado como derecho humano universal, podría ser en cierto modo el derecho humano definitivo, pues estaría conectado con el resto de derechos humanos y sería al mismo tiempo fundamento, condición y objetivo final de todos ellos. Es decir, el derecho humano a la paz necesita del resto de derechos humanos, pero a su vez, fiscalizaría y orientaría a estos.

Es una propuesta tremendamente ambiciosa en este sentido, pero es precisamente esta alta pretensión lo que lo convierte en un derecho único, pues su plena aplicación supondría de facto el respeto a todos los derechos humanos. Y si tenemos en cuenta la pobre observancia de los derechos humanos en numerosas partes del planeta, se presenta además como un derecho necesario, que exigiría rendir cuentas por violaciones de derechos humanos en cualquiera de sus niveles.

El derecho a la paz se engloba en los derechos de tercera generación, también llamados de solidaridad o vocación comunitaria, pero pretende que se reconozca y se interconecte al individuo, a las diferentes comunidades y a la sociedad en su conjunto, evitando la tradicional división en la titularidad de individuos y comunidades. Esta transversalidad, la intención de extenderse a las tres generaciones de derechos humano, es una de las principales virtudes del derecho humano a la paz y al mismo tiempo es uno de los mayores obstáculos que enfrenta de cara a su codificación por el recelo que suscita un derecho humano que sea vinculante a tantos niveles.

La transversalidad del derecho humano a la paz terminaría pues con la tradicional compartimentación y clasificación en niveles de los derechos humanos,fruto de la lucha de intereses histórica entre diferentes países.

No obstante, las objeciones por parte de algunos países, que también aducen las más que posibles dificultades que podría suponer la observancia y monitoreo del derecho humano a la paz, no deben eclipsar que su pretensión no es otra que velar y ser garante del resultado óptimo y objetivo fundamental de los derechos humanos: vidas plenas, dignas, con justicia y en paz.

La paz es el valor central de todos los derechos humanos y está presente durante todo su desarrollo histórico como una especie de brújula moral. Está presente de igual forma en los estatutos e instrumentos jurídicos de las Naciones Unidas, desde su misma Carta fundacional.

Resulta evidente pues, que un derecho humano a la paz no solo no es discorde con lo que se ha codificado hasta la fecha, sino que lo dota de coherencia y lo consigue integrar e interconectar, algo que resulta fundamental habida cuenta del trato diferenciado y preferencial que a los distintos tipos de derechos humanos se les ha dado según los intereses de cada país. Es una forma idónea de complementar y dar mayor profundidad a lo trabajado ya en las Naciones Unidas, en especial a la Declaración Universal de Derechos Humanos (DUDH).

Precisamente el Ex Secretario General de las Naciones Unidas, Kofi Annan, corroboraba que "la aparición del derecho a la paz es un objetivo noble, (que) no hay otro más grande, ni compromiso más profundo, ni mayor ambición que la prevención de los conflictos armados". Si bien se centra en una idea de paz negativa, esta declaración muestra de igual modo el compromiso en ciertos sectores de las Naciones Unidas con el derecho a la paz.

Del mismo modo que Gros Espiell, podemos considerar el derecho humano a la paz como una necesidad:

Una necesidad para la lucha individual y colectiva de todos y cada uno de nosotros por la paz en su más amplia acepción; una necesidad en la acción contra la violencia, en cualquiera de sus formas (directa, estructural, cultural) y cualquiera de sus niveles (personal 


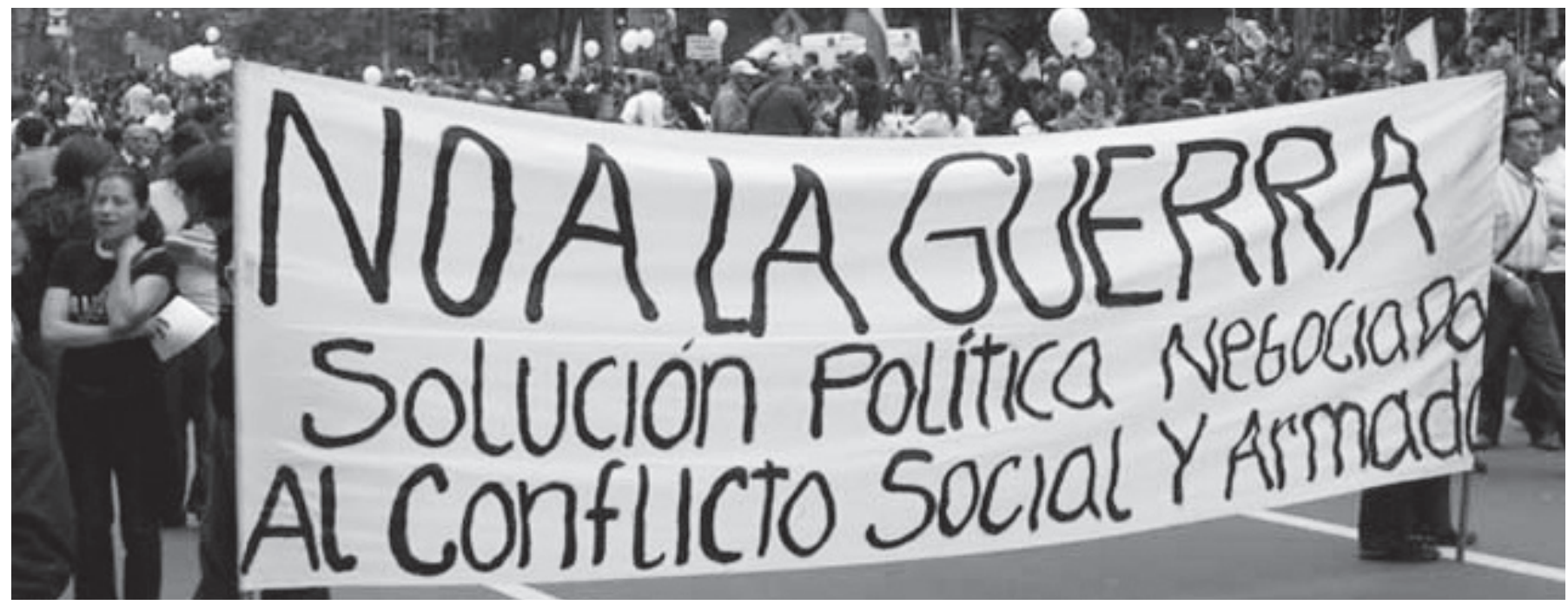

y social, nacional e internacional); y una necesidad para afirmar los valores de la tolerancia, la solidaridad y la cooperacióncon base en la justicia (1986: 541).

Por último, para justificar la existencia de un derecho a la paz, Gros Espiell escribe lo siguiente:

El derecho a la paz es total, general e indivisible. Por eso no tiene sentido afirmarlo y reconocerlo respecto de los Estados, los pueblos, las naciones y las minorías y negarlo empecinadamente en lo que se refiere a los individuos. Constituye hoy un absurdo jurídico y político no aceptar, entorpecer o dificultar el proceso irreversible hacia el reconocimiento pleno de un derecho a la paz del cual también sean necesarios titulares todos los seres humanos.

Crear la convicción de todo esto, abatir los muros de incomprensión que hasta hoy han impedido el reconocimiento pleno, integral y universal del derecho humano a la paz es un deber de todos. Es ser consciente de las necesidades que hoy existen y que son ineludibles en la lucha integral contra la guerra y la violencia en todas sus formas. (1986: $542)$.

\section{Codificación}

La codificación del derecho a la paz como derecho humano universal se encuentra en estos momentos en pleno debate por un Grupo de Trabajo nombrado del Comité de Derechos Humanos (CDH) de la Organización de las Naciones Unidas (ONU). Llevar esta propuesta a las Naciones Unidas (NNUU) ha sido el resultado de un largo y duro proceso de discusión y diálogo a muy diferentes niveles de la comunidad internacional, con el impulso fundamental de algunas organizaciones de la sociedad civil.

Hasta la fecha nohay un reconocimiento normativo lo suficientemente expreso del derecho humano a la paz, pero puede apreciarse tanto en el seno de las NNUU como en numerosas organizaciones de la sociedad civil un progresivo avance y compromiso con la materia con el paso de las décadas y un acercamiento a ese objetivo final de verlo plasmado en un derecho humano universal. Sin embargo, estos avances parecen haber llegado a un punto muerto, pues el Grupo de Trabajo de Consejo de Derechos Humanos de las NNUU está teniendo serios problemas para alcanzar consensos al respecto.

\section{Precedentes}

El derecho humano a la paz tiene sus principales precedentes en cartas, declaraciones y convenciones de diferentes organismos, documentos de diferente naturaleza jurídica y de distintos campos de aplicación que han ido admitiendo y evidenciando progresivamente la fuerte conexión entre la paz y los derechos humanos, y que han reconocido de formas implícitas y explícitas (aunque aún insuficientes) el derecho a la paz. Cabe destacar por un lado algunos de los documentos emanados de las NNUU desde su creación y, por otro, las numerosas contribuciones de organizaciones de la 


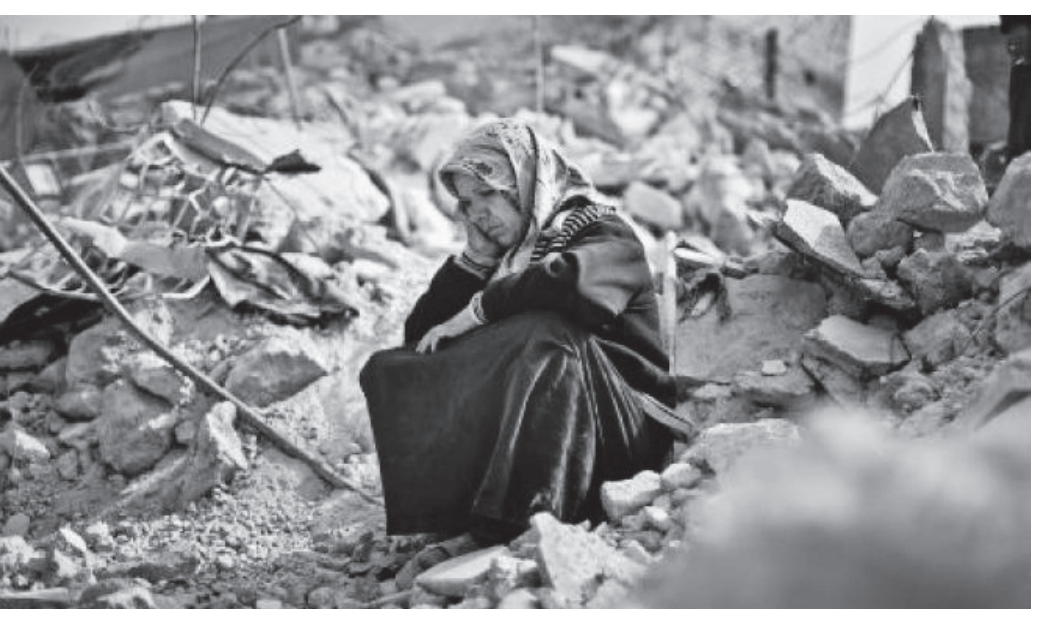

sociedad civil, así como organismos regionales, que no sólo han mantenido vivo el debate sino que muy a menudo han marcado el camino con sus propuestas.

Comenzando por los precedentes del ámbito de las NNUU, está en primer lugar la Carta de las Naciones Unidas, que es un referente básico del derecho humano a la paz, pues proclama como propósito fundamental del sistema de las Naciones Unidas la paz y la seguridad internacionales basadas en la solución pacífica de las controversias y la renuncia al uso de la fuerza.

En segundo lugar, la propia Declaración Universal de los Derechos Humanos (DUDH) hace un reconocimiento en su artículo 28 , ya bastante claro del derecho a la paz como un derecho humano: Toda persona tiene derecho a que se establezca un orden internacional en que los derechos proclamados en esta Declaración se hagan plenamente efectivos.

En tercer lugar, existe una resolución adoptada en 1976 por la Comisión de Derechos Humanos de las Naciones Unidas (resolución 5-XXXII), que proclamó ya entonces que toda nación y todo ser humano tienen el derecho inherente a vivir en paz.

En ese mismo sentido, cabría destacar otras dos resoluciones de la Asamblea General de las Naciones Unidas, igualmente relacionadas con el derecho a la paz. La primera, adoptada en $\mathbf{1 9 7 8}$ por la Asamblea General, titulada Declaración sobre la Preparación de las Sociedades para Vivir en Paz (33/73 del 25 de diciembre de1978), sostiene que el derecho a vivir en paz es un derecho de todas las naciones y de todos los individuos, independientemente de su raza, sexo, convicciones o idioma.

La otra es la resolución 39/11 de 12 de noviembre de 1984, que aprobó la Declaración sobre el Derecho de los Pueblos a la Paz y que es la primera vez que la Asamblea se refirió expresa y textualmente al derecho a la paz. Antes, en la resolución de 1978, se había usado la expresión "derecho a vivir en paz". Esta declaración de 1984 de la Asamblea General, dice en su artículo primero que "los pueblos de la tierra tienen un derecho sagrado a la paz".

Mantiene además que para asegurar el ejercicio del derecho de los pueblos a la paz, es indispensable que la política de los Estados tienda a la eliminación de las amenazas de guerra, sobre todo de guerra nuclear, hacia el abandono del recurso a la fuerza en las relaciones internacionales y hacia la solución pacífica de las controversias internacionales.

Estas declaraciones suponen un gran avance para la codificación del derecho humano a la paz, pero debemos recordar, no obstante, que las declaraciones de la Asamblea General de las NNUU no tienen valor jurídico si no son consagradas en tratados y pactos internacionales, solo un valor moral y político.

Por otro lado, la Unesco, que se ha revelado con los años como uno de los principales promotores de derecho humano a la paz, en la Declaración sobre la Enseñanza de los Derechos Humanos y en la Declaración sobre los Medios de Información, proclamó también el derecho a la paz.

Ya en el ámbito regional, en este caso el americano, existe de igual forma la proclamación del derecho a la paz. Este reconocimiento llega a través de una resolución de la Conferencia General del Organismo para la Proscripción de las Armas Nucleares en América Latina, que proclamó el derecho de "todas las personas, los Estados y la Humanidad a vivir en paz".

También en el ámbito regional, en el marco de la Organización de Estados Americanos, la Asamblea General de la OEA en 1998, en la Declaración de Caracas, reconoce la existencia del derecho humano a la paz.

Y por otro lado, está el importante referente de la Carta Africana sobre Derechos de los Hombres y de los Pueblos que no solamente proclama, enumera y 
garantiza la protección de los derechos de los individuos, sino también los derechos de los pueblos. Esta carta es el único tratado internacional, y por lo tanto, jurídicamente vinculante, que se refiere al derecho a la paz de forma explícita, y en su artículo 23, reconoce que: "todos los pueblos tendrán derecho a la paz y a la seguridad nacional e internacional". Es además pionera en expresar especial atención al derecho a la paz y al derecho al desarrollo (también de tercera generación), lo que ayudó en su momento a confirmar la relevancia de los derechos colectivos y solidarios.

Para terminar, desde la sociedad civil son muy numerosas las acciones, conferencias y declaraciones que se han llevado a cabo (Luarca, Barcelona, Londres...), siendo sin lugar a dudas la Declaración de Santiago (2010) la más relevante, pues aunó los esfuerzos previos e influyó de forma definitiva el devenir de la codificación del derecho humano a la paz. Además consiguió la adhesión de más de 800 organizaciones y probablemente el documento más completo respecto al derecho humano a la paz.

Esta declaración incluye los elementos esenciales del derecho humano a la paz y los desarrolla conforme a una concepción holística de la paz, comprendiendo tanto la paz negativa (ausencia de conflictos armados, desarme, objeción de conciencia) como la paz positiva (ausencia de violencia estructural derivada de las desigualdades económico-sociales en el mundo y en nuestras sociedades, así como ausencia de violencia cultural. En mi opinión es un documento fundamental, pues no sólo profundiza en el derecho humano a la paz, sino que lo clarifica, contextualiza y dota de coherencia, superando la indefinición y excesiva abstracción que tradicionalmente se le ha achacado.

\section{Codificación en NNUU}

Los precedentes arriba mencionados, junto con muchos otros, y sumados a ese interés constantemente manifestado por organizaciones de la sociedad civil $\mathrm{y}$ académicos de renombre, llevaron a que en julio de 2012, el Comité de Derechos Humanos (CDH) de las Naciones Unidas nombrara un Grupo de Trabajo intergubernamental para que redactara un proyecto de declaración sobre el derecho a la paz, sobre la base de la declaración adoptada por el Comité Asesor el 16 de abril de 2012.
Cabe destacar que el Consejo Asesor del CDH, compuesto por expertos independientes, incorporó el $85 \%$ de lo establecido en la Declaración de Santiago para su boceto de Declaración sobre el Derecho a la Paz, lo que atestigua la tremenda labor efectuada y la gran influencia que han tenido en este proceso las organizaciones de la sociedad civil, así como la credibilidad que reciben y merecen.

Desde entonces, el grupo de trabajo se ha reunido durante tres períodos de sesiones celebrados en 2013, 2014 y 2015, aunque hasta el momento no ha tenido éxito en su cometido. De hecho, al final de la tercera sesión del grupo, el presidente-relator concluyó sus funciones en 2015 presentando al Consejo de Derechos Humanos un proyecto de declaración que, para obtener el pretendido consenso, sacrificó tanto los elementos esenciales del derecho humano a la paz como el reconocimiento mismo de tal derecho. Ni siquiera con ese texto que cercenaba el derecho humano a la paz se obtuvo el codiciado consenso.

Del 11 al 15 de julio de 2016 tendrá lugar el cuarto período de sesiones del Grupo de Trabajo de las Naciones Unidas sobre el Derecho Humano a la Paz en Ginebra.

Cabría cuestionarse si un fracaso (falta de acuerdo) en la proclamación del derecho a la paz significaría un fracaso del propio derecho humano a la paz o más bien de las Naciones Unidas, organismo que, pese a ser el mejor instrumento con el que contamos por el momento, incurre en numerosas deficiencias e incoherencias a todos los niveles.

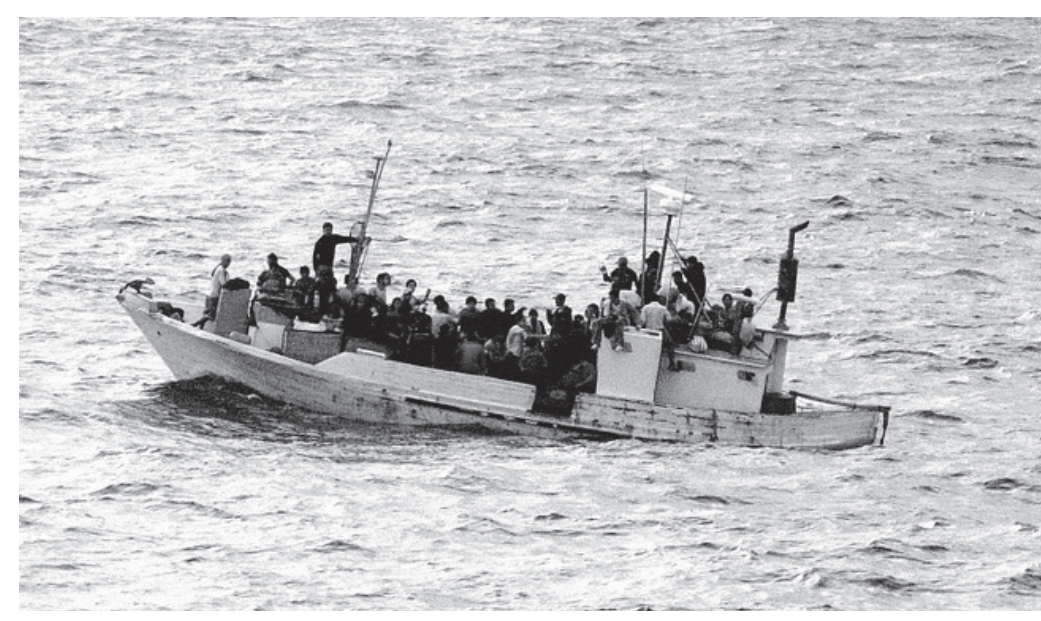




\section{Obstáculos y desafíos}

Siguiendo a Alemany Briz (1998), un primer grupo de objeciones se centra en la necesidad de insistir en los derechos ya reconocidos y que están lejos todavía de serrespetados en todo el mundo. Quienes son de esta opinión consideran que la proliferación de nuevos derechos humanos podría ser excesiva y podría poner en peligro a los anteriores.

Sin embargo, estas críticas sólo ponen de manifiesto la necesidad de conseguir una visión más transversal e integrada del contenido de los derechos humanos, y de sus tres generaciones, para lo cual se presenta ahora precisamente una gran oportunidad. El peligro de manipular o al menos enfatizar unos derechos frente a otros ya existía (y se ha hecho) antes.

Los derechos de la solidaridad no sólo no debilitan los derechos de generaciones anteriores, sino que deben ser contemplados como un prerrequisito para su ejercicio: la ausencia de paz o de desarrollo, o el agotamiento de los recursos medioambientales, impiden el pleno ejercicio de los derechos humanos de esta y futuras generaciones. En esta línea, Karel Vasak denomina a los nuevos derechos "derechos-síntesis", expresión que apunta a la integración y no a la oposición entre las diversas generaciones de derechos.

Federico Mayor Zaragoza (desde el ámbito de la UNESCO) propone con acierto respecto a la transversalidad de los $\mathrm{DDHH}$, la idea del triángulo interactivo:

La paz, el desarrollo y la democracia forman un triángulo interactivo, cuyos vértices se refuerzan mutuamente. Sin democracia, no hay desarrollo duradero. La pobreza y el estancamiento económico socavan la legitimidad democrática y dificultan la solución pacífica de los problemas (...) Ningún derecho se puede ejercer en medio de la guerra; ningún esfuerzo de transformación socioeconómica dará resultado en situaciones de conflicto; del mismo modo, es sumamente difícil garantizar la paz y la gobernabilidad democrática en ausencia de progreso -científico, económico, técnico- de todos los elementos de la sociedad.
Por otro lado, se han dado también discrepancias en torno a la dicotomía individuo-colectivo, una tensión que los derechos de tercera generación tratan de suavizar, pero que supone un grave obstáculo en el proceso de negociaciones. Esta dicotomía refleja la enorme influencia del liberalismo al tiempo que un cierto eurocentrismo, pues se ignoran otras tradiciones que dan más valor a la comunidad. Mientras que en otras culturas se puede observar una mayor conciencia del valor humano de la comunidad y de los deberes hacia ella, desde occidente se ha venido imponiendo desde hace siglos una cultura más basada en lo individual y en lo privado.

El hecho de que en el origen de la tradición occidental de los derechos humanos esté la defensa de la dignidad de toda persona frente a los abusos de la monarquía, nojustifica hoy que olvidemos los deberes hacia la comunidad para hacer posibles esos mismos derechos.

Vasak hace un buen resumen de esta situación:

Escarmentados por la experiencia del derecho al desarrollo que, cansados de luchas, acabaron reconociendo con desgana como un derecho humano, los occidentales, y ante todo algunos europeos, (ahora) aceptan difícilmente la idea de un derecho humano a la paz que sería necesariamente de la misma naturaleza que el derecho al desarrollo. Se aprecia la tenaz voluntad de los occidentales de quedarse en los derechos humanos tradicionales $\mathrm{y}$, principalmente los derechos civiles y políticos, base imprescindible de la democracia parlamentaria. (en Alemany Briz 1998: 11).

Otra opinión muy relevante al respecto es la de

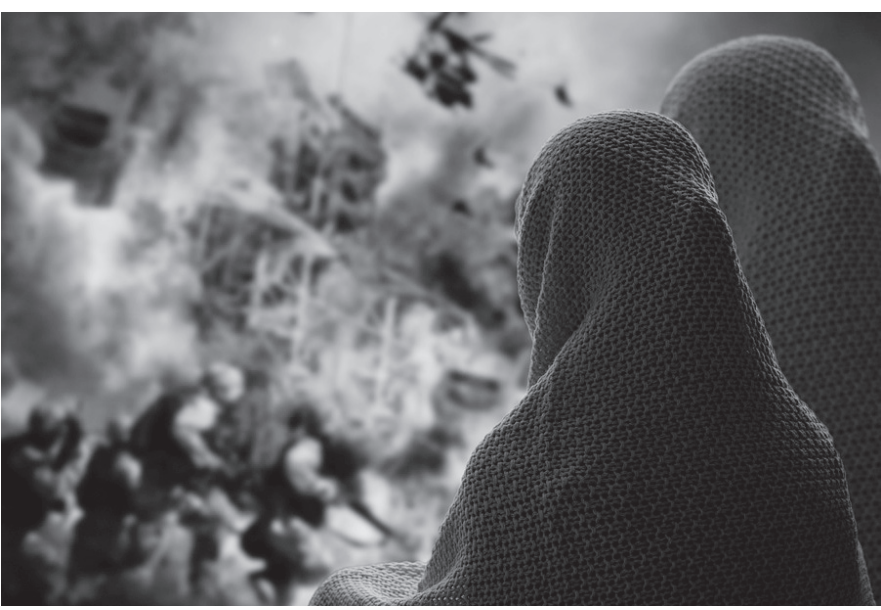


la Asociación Española del Derecho Internacional de los Derechos Humanos (AEDIDH), que ha tenido un papel clave para llevar el derecho humano a la paz a las NNUU, y desde la quese considera, con gran acierto en mi opinión, que en el proceso de codificación actual el consenso es imposible porque una minoría de países ricos, encabezada por los Estados Unidos y muchos países de la Unión Europea, rechazan sistemáticamente aceptar la existencia del derecho humano a la paz, sin aportar mayores explicaciones. En cambio, la gran mayoría de Estados miembros de las Naciones Unidas, de diferentes regiones del planeta, están a favor del reconocimiento internacional del derecho humano a la paz, en clara sintonía con la sociedad civil internacional.

Sin duda, ciertos intereses occidentales, principalmente económicos y militares, se verían seriamente afectados por una plena observancia de los derechos humanos y del derecho humano a la paz.

Estas discrepancias se plasman igualmente a la hora de acordar el contenido del derecho humano a la paz. En lugar de una visión más transversal, que considere la paz como la condición para el disfrute de todos los derechos humanos, hay algunos países que están intentando promover una concepción del derecho humano a la paz mucho más limitada y vacía de contenido.

Por poner algunos ejemplos, América Latina y numerosospaíses de África y deAsia abogan por que la violencia social ligada a la pobreza se considere como contraria al derecho a la paz. A los árabes, encabezados por Irak, les gustaría que la amenaza de intervención, el embargo o la ocupación de un territorio por la fuerza, pudieran registrarse como ataques contra el derecho a la paz. Otros envueltos en conflictos armados esperan que ese documento permita reducirla venta de armas.

En este sentido Alemany Briz defiende muy acertadamente que "no se debilita al Estado reconociendo el derecho humano a la paz;por el contrario, se fortalece al verdadero Estado democrático de derecho, justo ydefensor de los derechos humanos. Sólo el Estado arbitrario, fundado en la imposiciónantidemocrática, puede temer las consecuencias del reconocimiento del derecho humano a la paz". Parece evidente pues que estas críticas, reticencias y trabas carecen no solo de fundamento ético, sino también ideológico y racional.

\section{Conclusiones}

El derecho humano a la paz es en mi opinión, una constatación de nuestras mayores virtudes y miserias. Tras hacer un seguimiento al estado de la cuestión del derecho a la paz, me parece evidente que este debate reaviva y saca a la luz muchas de las contradicciones del género humano. La discusión sobre el derecho humano a la paz plasma el abismo entre el idealismo y el afán de algunos por mejorar las formas de convivir de los seres humanos, y el pragmatismo, cinismo e hipocresía de quienes hacen primar los intereses de unos pocos sobre los de la mayoría. Son quizás las mismas tensiones que cohabitan en el seno de las Naciones Unidas, aquellas que a menudo provocan inoperancia e incoherencias graves y que llevan a algunos, a considerarlo un sistema fallido. Pero, en el caso del derecho humano a la paz estas dicotomías me resultan especialmente sangrantes, porque me parece que ponen además, en peligro valores $\mathrm{y}$ derechos que por décadas hemos intentado hacer universales, y que el derecho humano a la paz vendría a consagrar, fortalecer e integrar.

Las tres generaciones de derechos humanos son un éxito muy cuestionable si su observancia y aplicación sufre de tantos sesgos y excepcionalidades como en la actualidad, y que profundizar en ellos mediante la proclamación de un derecho humano universal a la paz esté siendo cuestionado, debería ser motivo de sonrojo para todos, pero especialmente para quienes lo obstaculizan. No reconocerlo es considerar que existen derechos de primera y de segunda, y supone en consecuencia perpetuar y legitimar que existan ciudadanos de primera y de segunda.

En un momento como este, en el que los derechos humanos están en horas bajas y en el que nuestra capacidad de reacción (y también de sorpresa) ante tantas atrocidades está más en cuestión que nunca, considero que defender y promover un derecho humano a la paz es un gran paso en la dirección correcta, un avance clave para recuperar y revitalizar lo ya logrado en materia de derechos humanos y para dar un impulso a las visiones alternativas del mundo, a los que consideramos que podemos y debemos relacionarnos mejor los unos con los otros, a los que defendemos vidas dignas, justas, sostenibles y en paz. 